\title{
SCREENING CELL DESIGNS BASED ON SYNCHRONOUS MANUFACTURING
}

\author{
F. Javier Otamendi \\ Universidad Rey Juan Carlos, Campus Vicálvaro \\ Facultad de Ciencias Jurídicas y Sociales \\ Departamento Economía Aplicada I \\ Paseo Artilleros s/n \\ 28032 Madrid, Spain \\ E-mail: franciscojavier.otamendi@urjc.es
}

\section{KEYWORDS}

Discrete Event, Capacity, Stock Management, TOC.

\begin{abstract}
The combined analysis of an assembly cell using simulation models and theory-of-constraints is the aim of this article. The cell is a combination of a preparation and an operation phase which must keep the cycle time even under new product designs and demand mix. Simulation models are used to quantify the dynamic behaviour of the system under three configurations and theory-of-contraint concepts are used to illustrate the necessity to minimize the blockage of the input flows in order to guarantee the output flows. The chosen design synchronizes investments in equipment with the minimization of work-in-progress and the fulfilment of cycle times.
\end{abstract}

\section{INTRODUCTION}

New product designs usually involve adjustments in the processes both in terms of layout and capacity. This is the case of an automobile assembly plant that needs to modify its layout in order to incorporate new tasks in one of the main cells of the overall process.

The possibility of incorporating new different types of parts in the body puts too much stress in the assembly cell reaching the point where the throughput rate could be reduced considerably. In this particular case, part of the bodies will incorporate a new part, that need to be either manually or automatically assembled depending on the vehicle model.

There exists the possibility however of preassembling parts while the vehicle body is waiting in the input buffer to the assembly cell. The main objetive is to guarantee the current cycle time both at the entrance and the exit of the pre-assembly cell, which should coincide with the cycle time of the assembly cell (Kim et al 2010).

The layout of the current assembly process is depicted in Figure 1. After the bodies have gone through a series of operations, the rolling conveyor system moves the bodies to the buffer of the assembly cell. The input buffer is composed of a line buffer that may hold up to five units before it feeds three parallel lines of conveyors, in which several check operations are performed.

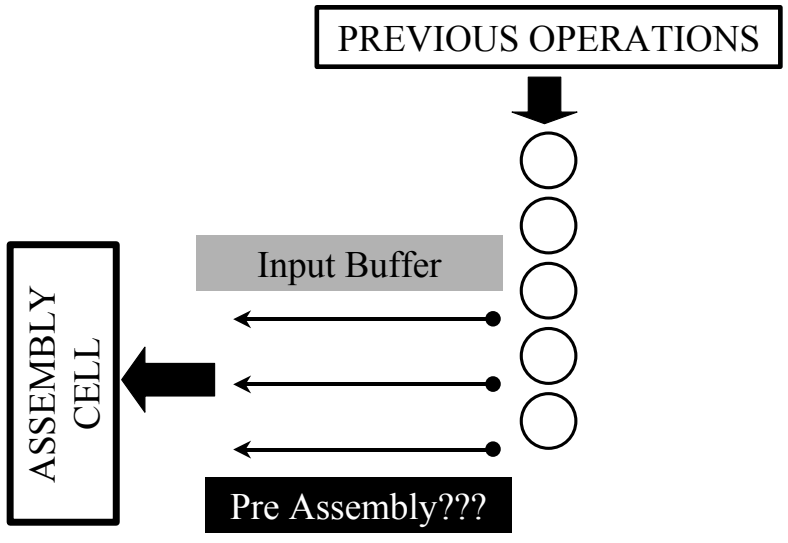

Figure 1. Current layout

There exists then a transfer system that moves the bodies into the assembly cell. The selection of the next body is controlled by a powerful information system which is in charge of maintaining and defining the proper sequence into the assembly cell.

The new product design has forced a redesign of the process, and that includes the necessity to perform preassembly operations in the buffer area, either manually, automatically or both. In fact, the aim of this study is to expand and redefine the waiting area. The reengineering task is the main topic covered in this article and includes the definition of different alternative layouts, their comparison using simulation and the selection in terms of the synchronization of cycle times as well as the minimization of the investment costs.

Synchronous manufacturing (also known as Optimized Process Technology - OPT, Theory of Contraints TOC or Drum-Buffer-Rope) is a manufacturing philosophy that aims at balancing the flows of each of the stages of the process and not their capacity 
(Goldratt 2004). Using simulation to understand synchronous systems is a current line of research (Gonzalez et al 2010, Rhee et al 2010, Wang et al 2010).

Section 2 includes a description of the three alternative designs that are going to be screened. Section 3 covers the quantitative simulation study, which includes the introduction of the available data, the definition of the decision criteria as well as the presentation of the results. Section 4 is then used to perform the comparison both quantitatively and qualitatively. Section 5 concludes.

\section{DESCRIPTION OF THE DESIGNS}

\section{Option A (3+1)}

The first possibility is to provide room for an additional line in parallel to the current three (Figure 2). The new part will be assembled in the new line, so the bodies that need to incorporate the part will take this preassembly line composed of two stations: one manual and the other automatic. The rest of the bodies will use the original lines. In the new line some bodies will suffer a delay

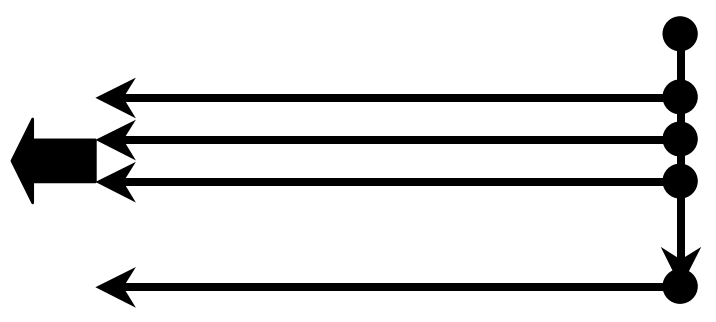

Figure 2. Layout for Option A

Of course, this layout releases stress out of the old lines, that have now less bodies to move. The quantitative study has to assess if the new line is able to cope with the demand for the new bodies. A capacity problem might appear also at the transfer line that is now four lines wide with the corresponding increase in movement and therefore in transfer times. The input throughput rate to the buffer system might also be in jeopardy if the new line is not able to cope with the new tasks, blocking the entrance and not allowing for the required cycle time at the assembly cell.

\section{Option B}

To provide flexibility and minimize the blocking probability at the entrance, the second option looks at the possibility of using the third old line also as an input buffer to the new line. This layout implies that the third line moves the bodies in the opposite direccion to the flow. If the new line is full, the bodies that require pre-assembly will take the second line and then the third before they reach the new buffer line.

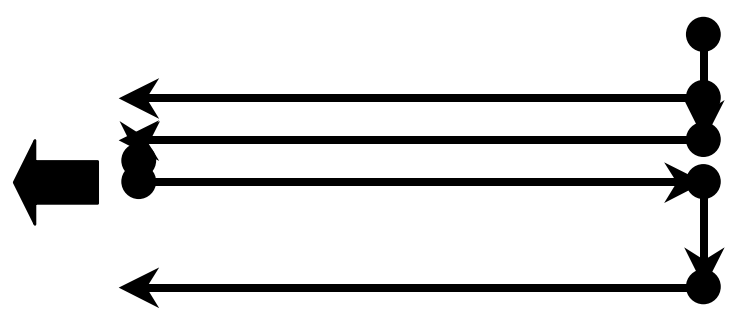

Figure 3. Layout for Option B

The stress is now put on the bodies that will not go through the new operation. The feasibility of this design clearly depends on the production mix, as always, but even more so in this case.

\section{$\underline{\text { Option C }}$}

The last option is to differentiate between the two types of bodies by including an additional line in which the manual assembly of parts could be performed, leaving the automatic pre-assembly for the last line (Figure 5).

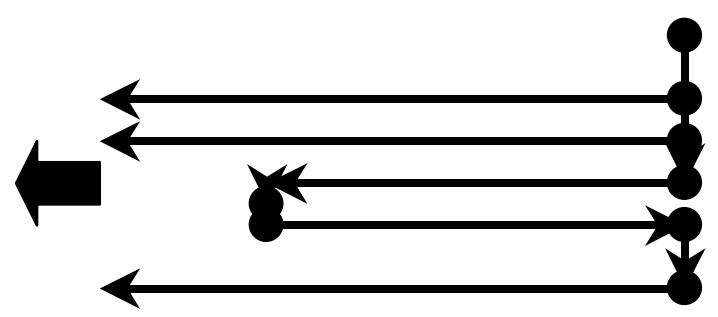

Figure 4. Layout for Option C

This extra investment with a higher cost will a priori allow for a higher throughput with more flexibility and less blockage at the entrance.

\section{SIMULATION OF THE DESIGNS}

\section{$\underline{\text { Available data }}$}

The first and most important piece of information is that of the demand. The reason for the study is the new product mix that has resulted from the possibility of including an additional part in the vehicle. This extra part might considerably vary the demand mix and therefore the capacity potential of the assembly and the pre-assembly cell. The demand in this case is not known but forecasted, and in fact, the reason for the study is to assess the demand (capacity) that each design might hold. On this screening phase, the total demand is maintained as its current level of 1 every 60 seconds (input and output cycle time) but with the mix included in Table 1 according to the new parts and resources that are needed to perform the pre-assembly. 
Table 1. Demand Mix

\begin{tabular}{lc}
\hline TYPE & PERCENTAGE \\
\hline MANUAL & $9.0 \%$ \\
AUTOMATIC & $29.5 \%$ \\
BOTH & $3.8 \%$ \\
NONE & $57.7 \%$ \\
\hline
\end{tabular}

The second set of data is that of the sequence. Due to technology restriction, only one manual operation might be performed every three bodies. Also, and due to set-ups only two robot operations could be performed on a row. Combining all the restrictions, a repeated sequence of 30 bodies has been used as a base sequence to perform the comparisons.

Process and movement rates as well as distances are also needed. Conveyor speeds, set-up and assembly times are available in the process specifications. Breakdowns and maintenance data is also available as might be critical (Patti and Watson 2010).

\section{$\underline{\text { Output Criteria }}$}

The alternative designs are going to be evaluated according to the following criteria:

- Percent Blockage at entrance

- Occupation of "Entry Transfer"

- Occupation of "Automatic" operation

- Occupation of "Manual" operation

- Occupation of "Ouput Transfer"

- Average and Maximum Number at Input Buffer before Entry Transfer

- Average and Maximum Number of Bodies in New Area

- Average Cycle Time

- Possible Flow Improvement = Idle Percentage (Starving) for Entry to Assembly

These criteria relate to the evaluation of synchronous manufacturing (TOC). Under this philosophy, the cycle time has to correspond with the demand and it should provoke a tense, lean flow at each and every stage of the process. Then, the occupation of the all the processes should be balanced and about $90 \%$ of utilization, including set-ups and downtimes (Wu et al 2010).

\section{$\underline{\text { Results }}$}

The results for each of the simulated options are shown in graphical form in Figure 5, Figure 6 and Figure 7, for Options $\mathrm{A}, \mathrm{B}$, and $\mathrm{C}$ respectively. The graphs correspond to the MsExcel interface that was built to easily transfer data to and from the simulator.

Option A shows, as foreseen a very high occupation rate in the new line, which provokes a high blockage percentage at the entrance. The output rate (cycle time) however is enough to keep the pace of the assembly cell, which is the one that cannot cope with more work due to its high downtime.

Option B puts too much stress on the old system, blocking the entrance above $50 \%$ of the time. The input cycle time dictates then the output cycle time, which is too high allowing for idle time in the assembly cell (11\%).

Option $\mathrm{C}$ is more balanced with cycle times similar to those of the assembly cell, but occupation rates to close to $100 \%$.

\section{COMPARISON}

Table 2 summarizes the behaviour of the three designs. Buffer space refers to the maximum designed capacity whereas average and maximum bodies correspond to the dynamic behaviour. The cycle time corresponds to the throuput potential and the improvement to the blockage ratio, which could be eliminated through investments or further process improvement.

Table 2. Comparison of alternatives

\begin{tabular}{rrrr} 
& \multicolumn{3}{c}{ OPTION } \\
& A & B & C \\
BUFFER SPACE & 31.0 & 31.0 & 36.0 \\
AVERAGE BODIES & 21.8 & 14.8 & 25.3 \\
MAXIMUM BODIES & 26.0 & 17.0 & 29.0 \\
CYCLE TIME (seconds) & 66.5 & 75.0 & 67.1 \\
FEASIBLE IMPROVEMENT (\%) & 0.2 & 11.0 & 0.2
\end{tabular}

The main conclusions are the following

- Option A and Option C show similar cycle times. The call is to disregard Option B due to subpar cycle time.

- The cycle time is higher than the required 60 seconds, both consistent with the assembly cell time, in both Option A and Option $\mathrm{C}$ due to:

- Breakdowns of the assembly process

- Breakdowns of the manual and the robot operations

- The key controlling factor is therefore the cycle time of the following assembly system. The bottleneck is at the end following the theory of constraints (Goldratt 2004)

- Option A shows a lower average number of bodies when comparing to Option $\mathrm{C}$ (spaces 31 vs 36; average approxinmately 21 vs 25), so the solution is cheaper in terms of work-inprocess.

- Option A gives a feasible and viable solution with a lowest conveyor investment cost.

- Option A might be upgraded to option C if required in the future for capacity increase or additional works. 


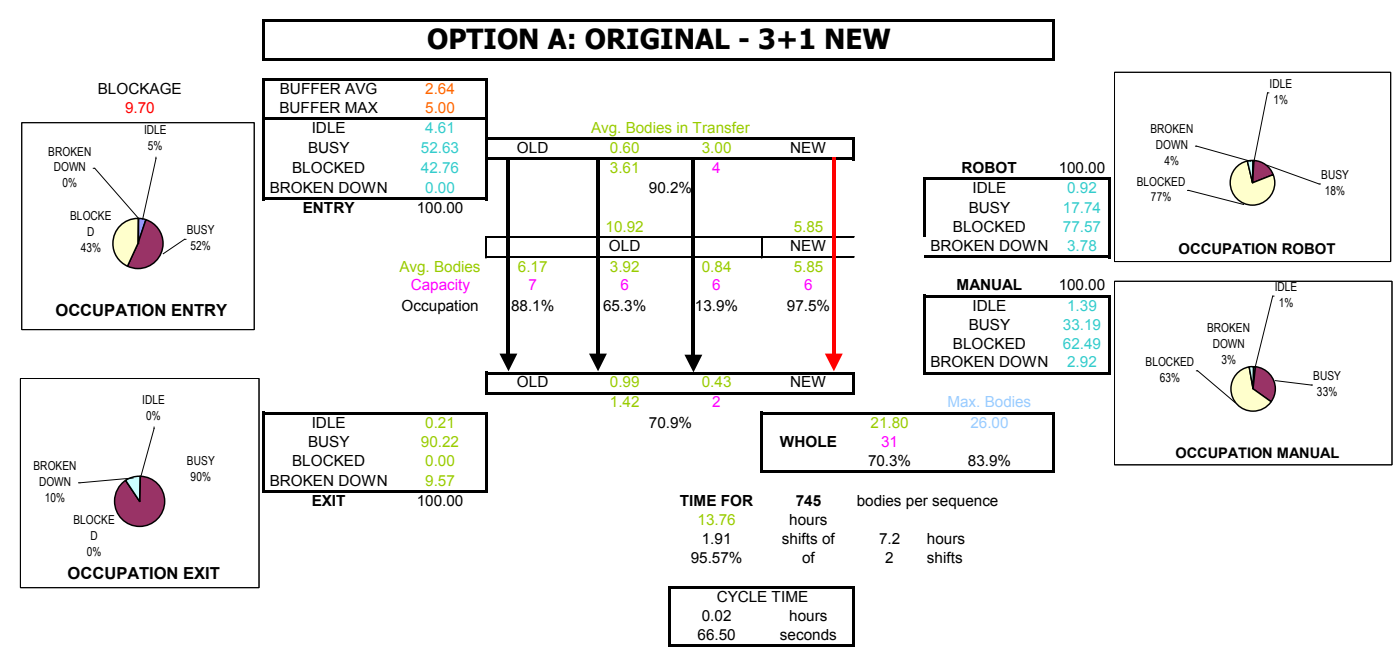

Figure 5. Results for OptionA

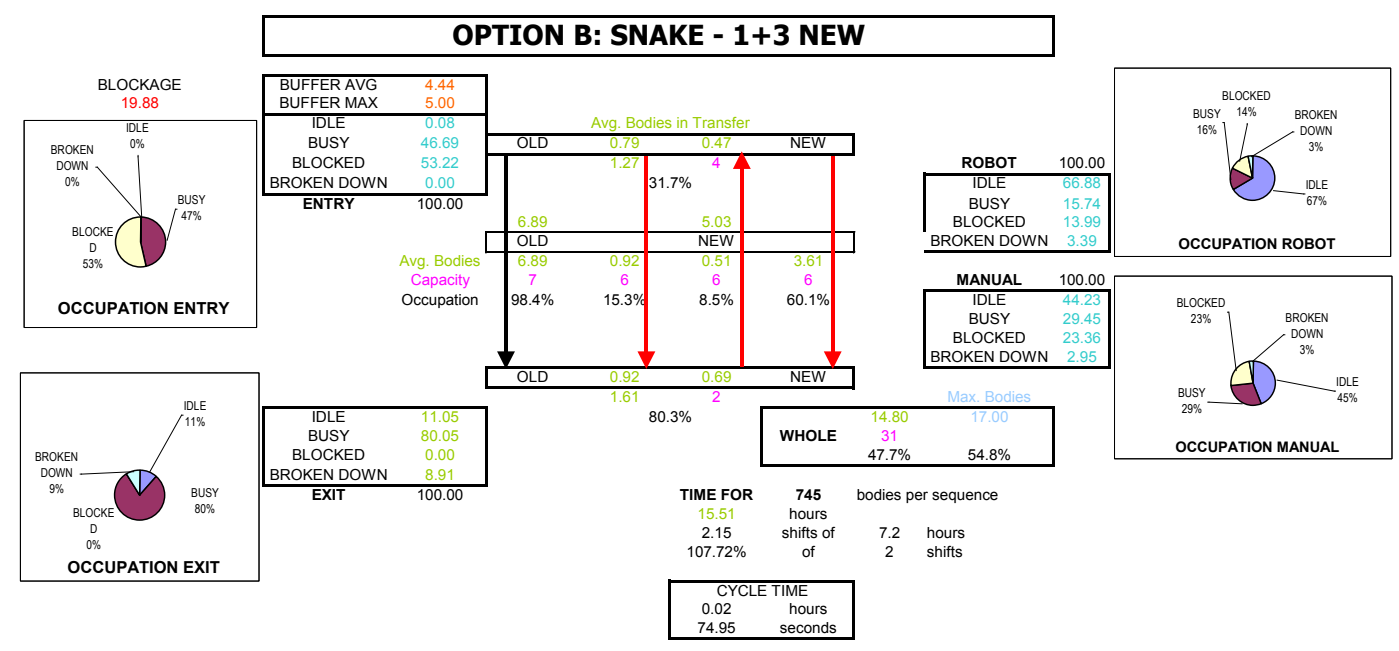

Figure 6. Results for Option B

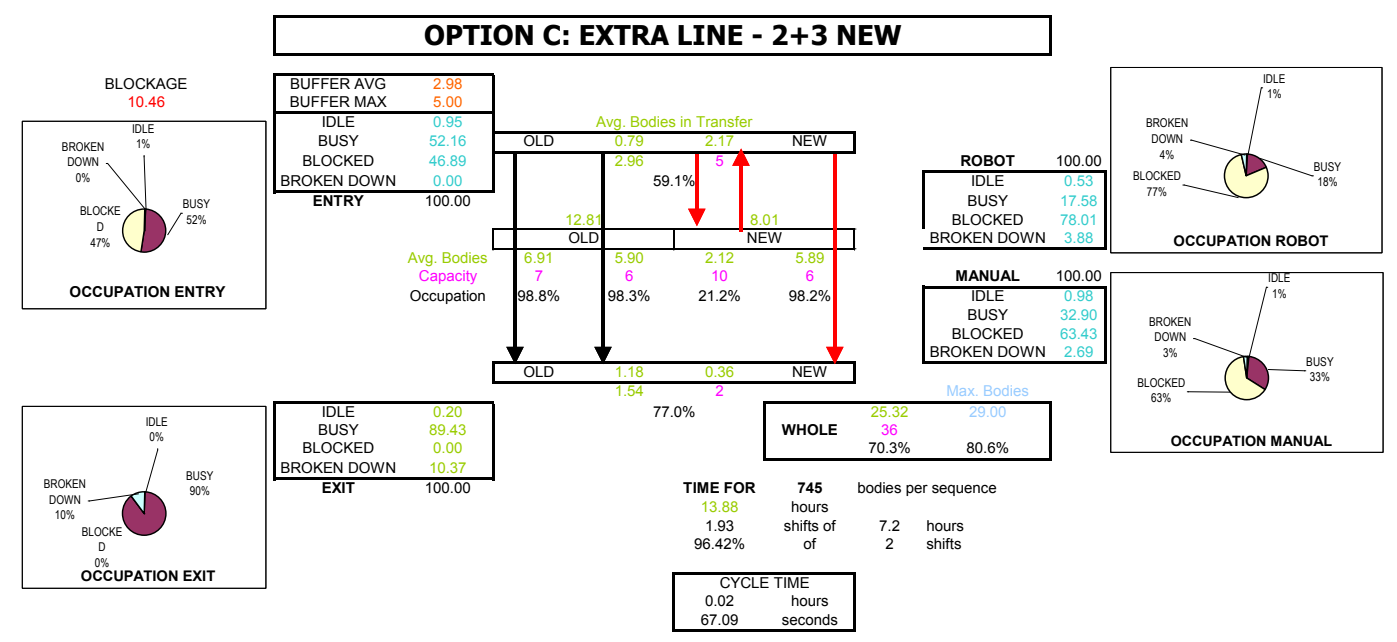

Figure 7. Results for Option C 


\section{CONCLUSIONS}

The simulation study shows the weak points of the assembly process, pinpointing the necessity to address a quality assurance, balancing and improvement process. The applicability of theory-of-constraints concepts in which there has to be a synchronization between input and output flows is also highlighted. Both Options A and C also follow TOC principles by making the bottleneck be the last stage, that of the final assembly process. Work-in-process is optimum also as a by-product.

\section{REFERENCES}

Goldratt, E.M. 2004. “The Goal”. North River Press.

Gonzalez-R PL, Framinan JM, Ruiz-Usano R. 2010. A Multi-Objective Comparison Of Dispatching Rules In A Drum-Buffer-Rope Production Control System. International Journal of Computer Integrated Manufacturing 23(2), 155-167.

Kim S, Cox JF, Mabin VJ. 2010. An Exploratory Study Of Protective Inventory In A Re-Entrant Line With Protective Capacity. International Journal Of Production Research 48(14), 4153-4178.

Patti AL, Watson KJ. 2010. Downtime variability: the impact of duration-frequency on the performance of serial production systems, International Journal Of Production Research 48(19), 5831-5841.

Rhee SH, Cho NW, Bae H. 2010. Increasing The Efficiency Of Business Processes Using A Theory Of Constraints, Information Systems Frontiers 12(4), 443-455.

Wang YH, Cao J, Kong LX. 2009. Hybrid Kanban/Conwip Control System Simulation and Optimization Based on Theory of Constraints, 2009 IEEE International Conference On Intelligent Computing And Intelligent Systems, Proceedings, VOL 2, 666-670.

Wu HH, Chen CP, Tsai CH, Yang, CJ. 2010. Simulation And Scheduling Implementation Study Of TFT-LCD Cell Plants Using Drum-Buffer-Rope System. Expert Systems With Applications 37(12), 8127-8133.

\section{AUTHOR BIOGRAPHIES}

JAVIER OTAMENDI received the B.S. and M.S. degrees in Industrial Engineering at Oklahoma State University, where he developed his interests in Simulation and Total Quality Management. Back in his home country of Spain, he received a B.S. in Business Administration and a Ph.D. in Industrial Engineering. He is currently a simulation and statistics consultant and university professor at the Rey Juan Carlos University in Madrid. 